declining? Systematic review of epidemiological studies. Allergy 2010;65(2):15267. http://dx.doi.org/10.1111/j.1398-9995.2009.02244.x

82. Weinmayr G, Weiland SK, Bjorksten B, et al. Atopic sensitization and the international variation of asthma symptom prevalence in children. Am J Respir Crit Care Med 2007;176(6):565-74. http://dx.doi.org/10.1164/rccm.200607-9940C

83. Platts-Mills TA, Cooper PJ. Differences in asthma between rural and urban communities in South Africa and other developing countries. I Allergy Clin Immunol 2010;125(1):106-07. http://dx.doi.org/10.1016/j.jaci.2009.10.068

84. Cockcroft DW. Bronchial challenge testing. In: Middleton's Allergy: Principles and Practice. Adkinson, 2008.

85. Calvert J, Burney P. Effect of body mass on exercise-induced bronchospasm and atopy in African children. J Allergy Clin Immunol 2005;116(4):773-9. http://dx.doi.org/10.1016/j.jaci.2005.05.025

86. Kiraz K, Kart L, Demir R, et al. Chronic pulmonary disease in rural women exposed to biomass fumes. Clin Invest Med 2003;26(5):243-8.

87. WHO. Indoor air thematic briefing 3: Solutions for indoor air pollution problem. World Health Organization, 2006.

88. Barnes BR, Mathee A, Krieger L, Shafritz L, Favin M, Sherburne L. Testing selected behaviors to reduce indoor air pollution exposure in young children. Health Educ Res 2004;19(5):543-50. http://dx.doi.org/10.1093/her/cyg075
89. WHO. Fuel for life: household energy and health. World Health Organization, 2006.

90. Naeher LP. Biomass-fueled intervention stoves in the developing world: potential and challenges. Am J Respir Crit Care Med 2009;180(7):586-7. http://dx.doi.org/10.1164/rccm.200907-1115ED

91. Intermediate Technology Development Group. Kenya Smoke and Health Project 1998-2001. 2003.

92. Bailis R, Ezzati M, Kammen DM. Mortality and greenhouse gas impacts of biomass and petroleum energy futures in Africa. Science 2005;308(5718):98-103. http://dx.doi.org/10.1126/science.1106881

93. Kengne AP, Sobngwi E, Fezeu LL, Awah PK, Dongmo S, Mbanya JC. Nurse-led care for asthma at primary level in rural sub-Saharan Africa: the experience of Bafut in Cameroon. J Asthma 2008;45(6):437-43. http://dx.doi.org/10.1080/ 02770900802032933

94. de Savigny D, Kasale H, Mbuya C, Reid G. Fixing Health Systems: Tanzania Essential Health Interventions Project. Focus 2004.

95. Ottmani SE, Scherpbier R, Pio A, Chaulet P. Practical Approach to Lung Health (PAL). 2005.

96. Ait-Khaled N, Enarson DA, Bencharif N, et al. Treatment outcome of asthma after one year follow-up in health centres of several developing countries. Int J Tuberc Lung Dis 2006;10(8):911-16.

\title{
COMMENTARY
}

\section{Non-communicable diseases and their importance in low and middle income countries}

\author{
*Sian Williamsa, Miguel Roman Rodriguez ${ }^{\mathrm{b}, \mathrm{c}}$ \\ a Executive Officer, International Primary Care Respiratory Group \\ ${ }^{b}$ President, International Primary Care Respiratory Group \\ c Son Pisa Primary Care Health Centre, Palma de Mallorca, Spain
}

Non-communicable diseases (NCDs) have become an important health burden not only in high income countries where population ageing is a major contributory factor - but also in low and middle income countries (LMICS). Yet they receive insufficient attention from the healthcare community and governments. $80 \%$ of all NCDs occur in LMICs, causing 8 million premature deaths annually from the major NCD risk factors. They are also a major cause of poverty and an urgent development issue, with LMICs carrying the biggest burden. However, less than $3 \%$ of the global development assistance for health goes to prevention and control of NCDs. ${ }^{1}$ The International Primary Care Respiratory Group (IPCRG) has joined the NCD Alliance as part of our campaign for chronic respiratory diseases (CRDs), smoking cessation, and the role of primary care, to be prioritised by national governments and funding agencies so that additional resources are allocated given their economic and health impact (http://www.theipcrg.org/resources/resources_cdmNCDalliance. php). The NCD Alliance's call for action is for the United
Nations at its Summit in September 2011 to commit to global action on NCDs.

Tobacco dependence and CRDs such as asthma and chronic obstructive pulmonary disease (COPD) affect hundreds of millions of people all over the world, the majority living in LMICS or deprived populations. ${ }^{2}$ Current data on the impact and prevalence of asthma and COPD in these populations are limited; they are under-diagnosed and under-treated, and have therefore not been seen as major health problems. Many sub-Saharan African countries are good examples of how multiple urgent priorities such as the Millennium Development Goals (http://www.un.org/millenniumgoals/poverty.shtml), natural disasters or ethnic conflicts lead to lack of funding, research and knowledge about the prevalence and burden of CRDs and consequent inadequate application of the evidence of effective interventions. Primary prevention activity is also insufficient.

Here, van Gemert et al. ${ }^{3}$ present an excellent review of the published data to assess the prevalence of asthma, COPD and

\footnotetext{
* Corresponding author: Ms Sian Williams, Executive Officer, IPCRG, c/o PO Box 11961, Westhill, AB32 9AE,Scotland Tel: +44 (0)7980 541664 E-mail: ExecOfficer@theipcrg.org
} 
respiratory risk factors (including indoor pollution) in subSaharan populations. They show that the burden of CRDs is rising and that the association with exposure to biomass fuel use and the dose-response relationship needs further evaluation to inform effective interventions. Qualitative and quantitative research will be essential to provide policymakers with convincing evidence of the impact of CRDs on local communities and for the implementation of low-cost, locally appropriate and sustainable interventions to control these diseases and their risk factors.

These findings are clearly in line with the IPCRG Research Needs Statement ${ }^{4}$ that highlights unanswered questions about the management of respiratory diseases that are of importance to practising primary care clinicians worldwide. Some of these questions are related to LMICs and are supported by van Gemert et al.'s conclusions:

- What is the extent of under-diagnosis of CRDs in local communities?

- What are the important environmental risk factors, including indoor biomass fuel smoke, cigarette smoking and environmental pollution, aeroallergens, dietary and lifestyle factors?

- What is the impact of locally-tailored community-level measures to decrease exposure to indoor smoke and reduce harm?

- How can rural and remote areas or LMICs diagnose and manage CRDs with limited or no availability of diagnostic tests?

- How, and to what degree, are CRD action plans implemented in various communities, especially in LMICs; how might they be locally tailored and how do they impact on CRD morbidity and mortality?

The IPCRG E-faculty programme equips one primary care research-aspiring country at a time with the skills to conduct high quality original research desined to provide some answers to these primary care questions. As part of that programme, the FRESH-AIR study has been piloted in Vietnam to understand the clinical effectiveness and cost-effectiveness of case-finding, smoking cessation and indoor biomass smoke-reduction strategies in resource-limited primary care settings. A derivation, the FRESH-AIR pilot survey Uganda, has just been completed with IPCRG support, working with local teams and using solarpowered devices to identify the burden of lung disease in the community. Leading a local team, van Gemert and colleagues tested a qualitative survey using focus group discussions - involving men, women and community leaders, as well as key healthcare workers - to assess the beliefs and attitudes concerning respiratory health, smoking, traditional ways of cooking, and the use of spirometry in a rural area of Uganda. The results were presented at the recent 2 nd IPCRG International Scientific Meeting held in Amsterdam in May 2011; ${ }^{5}$ these show that knowledge of asthma and COPD, and knowledge of symptoms such as chronic cough and their contributory factors such as biomass fuel use and smoking, is poor and has to be increased.

The IPCRG will continue to play its part in investing in LMICs by supporting initiatives such as van Gemert et al.'s to improve understanding of the scale of the problem and the best value solutions. ${ }^{6}$ In addition, it has now launched its E-Quality programme (http://www.theipcrg.org/educprog/equality.php) to test effective educational interventions in line with the Lancet Commission on Education?

\section{Conflicts of interest}

None

\section{References}

1. Puska P. Non-communicable disease-neglected diseases in global health work? Eur J Public Health 2011;21(3):269. http://dx.doi.org/10.1093/eurpub/ckr052

2. WHO Global alliance against respiratory diseases: action plan 2008-2013. World Health Organization, 2008

3. van Gemert F, van der Molen T, Jones R, Chavannes N. The impact of asthma and COPD in sub-Saharan Africa. Prim Care Respir J (2011);20(3):240-8. http://dx.doi.org/10.4104/pcrj.2011.00027

4. Pinnock H, Thomas M, Tsiligianni I, et al. The International Primary Care Respiratory Group (IPCRG) Research Needs Statement 2010. Prim Care Respir J 2010;19(Suppl 1):S1-S20. http://dx.doi.org/10.4104/pcrj.2010.00021

5. 2nd IPCRG International Scientific Meeting, "Primary Care at the leading edge", Thursday 26th May (Evening) - Friday 27th May 2011, Amsterdam, Abstracts selected for publication in the Primary Care Respiratory Journal. Prim Care Respir J 2011;20(2):A1-A13. http://dx.doi.org/10.4104/pcrj.2011.00053

6. Watts G. An extra dollar can go a long way. BMJ 2004;329:1126 http://dx.doi.org/10.1136/bmj.329.7475.1126

7. Frenk J, Chen L, Bhutta ZA, et al. Health professionals for a new century: transforming education to strengthen health systems in an interdependent world. Lancet 2010;376(9756):1923-58.

Commissioned article; not externally peer-reviewed; accepted 1st August 2011; online 17th August 2011

(C) 2011 Primary Care Respiratory Society UK. All rights reserved. S Williams and M Roman Rodriguez. Prim Care Respir J 2011; 20(3):248-249.

http://dx.doi.org/10.4104/pcrj.2011.00077

\section{Available online at http://www.thepcrj.org}

